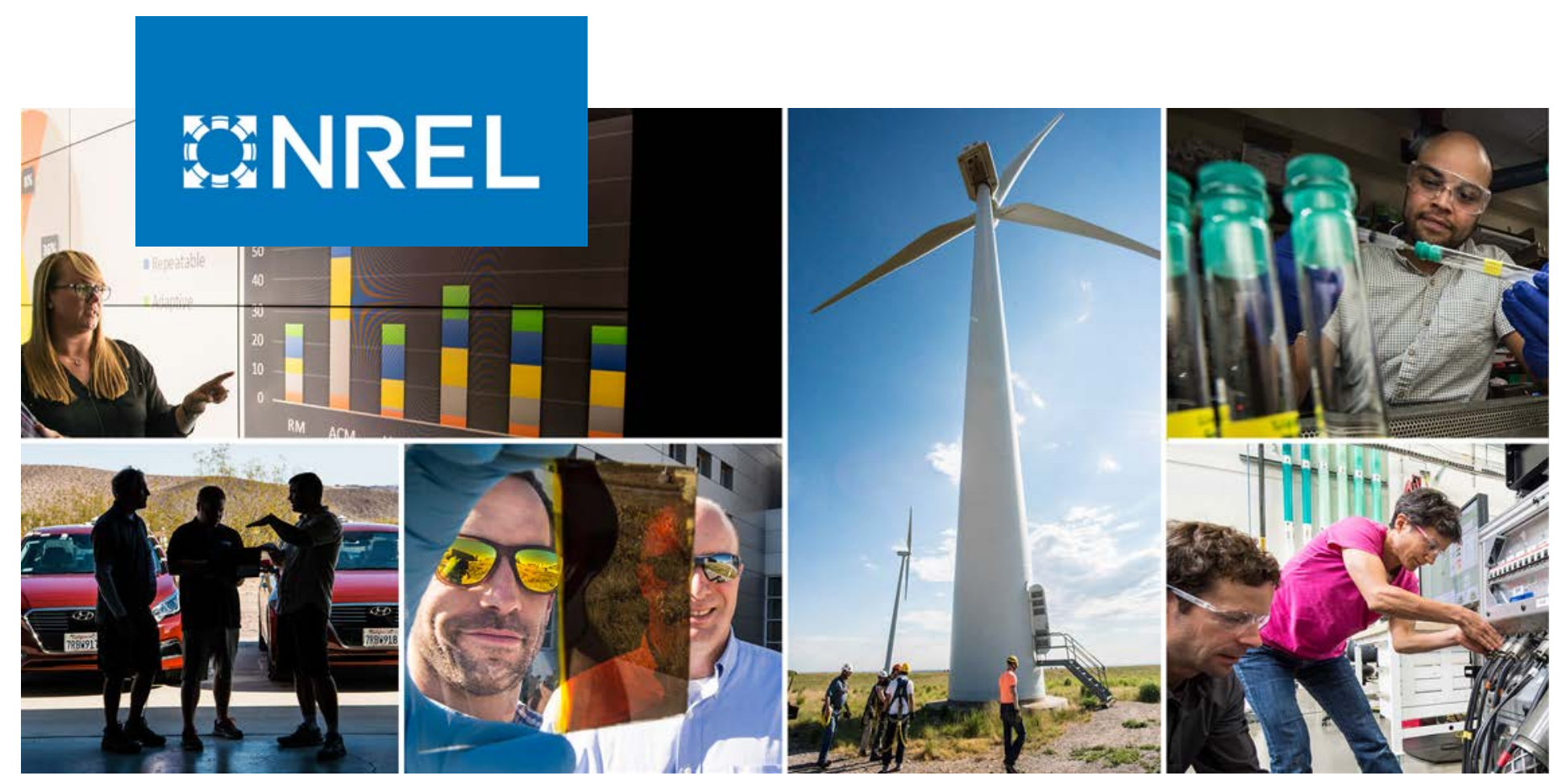

\title{
Floating Photovoltaic System Cost Benchmark: Q1 2021 Installations on Artificial Water Bodies
}

Vignesh Ramasamy and Robert Margolis

National Renewable Energy Laboratory

NREL is a national laboratory of the U.S. Department of Energy

Office of Energy Efficiency \& Renewable Energy

Operated by the Alliance for Sustainable Energy, LLC

This report is available at no cost from the National Renewable Energy Laboratory (NREL) at www.nrel.gov/publications.
Technical Report

NREL/TP-7A40-80695

October 2021 


\section{GNREL}

\section{Floating Photovoltaic System Cost Benchmark: Q1 2021 Installations on Artificial Water Bodies}

Vignesh Ramasamy and Robert Margolis

National Renewable Energy Laboratory

\section{Suggested Citation}

Ramasamy, Vignesh and Robert Margolis. 2021. Floating Photovoltaic System Cost Benchmark: Q1 2021 Installations on Artificial Water Bodies. Golden, CO: National Renewable Energy Laboratory. NREL/TP-7A40-80695.

https://www.nrel.gov/docs/fy22osti/80695.pdf.

NREL is a national laboratory of the U.S. Department of Energy Office of Energy Efficiency \& Renewable Energy Operated by the Alliance for Sustainable Energy, LLC

This report is available at no cost from the National Renewable Energy Laboratory (NREL) at www.nrel.gov/publications.

Contract No. DE-AC36-08GO28308
Technical Report NREL/TP-7A40-80695 October 2021

National Renewable Energy Laboratory 15013 Denver West Parkway Golden, CO 80401 303-275-3000 • www.nrel.gov 


\section{NOTICE}

This work was authored by the National Renewable Energy Laboratory, operated by Alliance for Sustainable Energy, LLC, for the U.S. Department of Energy (DOE) under Contract No. DE-AC36-08GO28308. Funding provided by the U.S. Department of Energy Office of Energy Efficiency and Renewable Energy Solar Energy Technologies Office. The views expressed herein do not necessarily represent the views of the DOE or the U.S. Government.

This report is available at no cost from the National Renewable Energy Laboratory (NREL) at www.nrel.gov/publications.

U.S. Department of Energy (DOE) reports produced after 1991 and a growing number of pre-1991 documents are available free via www.OSTI.gov.

Cover Photos by Dennis Schroeder: (clockwise, left to right) NREL 51934, NREL 45897, NREL 42160, NREL 45891, NREL 48097, NREL 46526.

NREL prints on paper that contains recycled content. 


\section{Acknowledgments}

This work was authored by the National Renewable Energy Laboratory (NREL), operated by Alliance for Sustainable Energy, LLC, for the U.S. Department of Energy (DOE) under Contract No. DE-AC36-08GO28308. Funding was provided by DOE's Office of Energy Efficiency and Renewable Energy Solar Energy Technologies Office. The views expressed in the article do not necessarily represent the views of the DOE or the U.S. Government. The U.S. Government retains and the publisher, by accepting the article for publication, acknowledges that the U.S. Government retains a nonexclusive, paid-up, irrevocable, worldwide license to publish or reproduce the published form of this work, or allow others to do so, for U.S. Government purposes.

We would like to acknowledge Paul Basore and Andrew Dawson (DOE); and Nathan Lee, Nate Blair, and Adam Warren (NREL) for reviewing this report, as well as Jarett Zuboy and Caitlin Dorsey (NREL) for editing this report and Alfred Hicks (NREL) for creating some of the graphics. We would also like to thank Andres Franco (ISI Floating Systems), Chris Bartle (Ciel et Terre), Stetson Tchividjian (D3Energy), Charles Gery (Seaflex), Stanislas Merlet (Multiconsult), Felix Gorintin (Innosea), Toni Weigl (Baywa), and Jairo Criollo (Noria Energy) who allowed us to interview them for this report and took the time to provide input data and review the report. 


\section{List of Acronyms}

AC

DC

DOE

EPC

FPV

$\mathrm{GW}_{\mathrm{DC}}$

ha

HDPE

IP

ITC

$\mathrm{kV}$

$\mathrm{kVA}$

LCOE

LPV

$\mathrm{m}$

$\mathrm{m} / \mathrm{s}$

$\mathrm{MW}_{\mathrm{AC}}$

$M W_{D C}$

MWh

NREL

O\&M

psf

PV

SBOS

$\mathrm{V}_{\mathrm{DC}}$

$\mathrm{W}_{\mathrm{DC}}$ alternating current

direct current

U.S. Department of Energy

engineering, procurement, and construction

floating photovoltaic

gigawatts, direct current

hectare

high-density polyethylene

Ingress Protection

investment tax credit

kilovolt

kilovolt-ampere

levelized cost of energy

land-based photovoltaic

meter

meters per second

megawatt, alternating current

megawatt, direct current

megawatt-hour

National Renewable Energy Laboratory

operations and maintenance

pounds per square foot

photovoltaic

structural balance of system

volt, direct current

watt, direct current 


\section{Executive Summary}

In the last 10 years, the installed cost of U.S. utility-scale photovoltaic (PV) systems has declined by more than half, driven largely by improvements in module efficiency and balance-of-system cost (Feldman et al. 2021). Most of these systems have been sited over bare land (Horowitz et al. 2020). However, where land use is constrained, land is not easily accessible, or land leasing is expensive, developers are installing floating PV (FPV) on water bodies. In addition to reducing land use competition, FPV can potentially provide advantages such as reducing evaporation from the water bodies, enabling dual-use installation with aquaculture, and increasing energy yield (World Bank Group 2019). FPV has experienced significant growth since 2016.

In this report, we conduct a bottom-up analysis of the installed costs for FPV systems deployed on artificial water bodies under average site conditions (wind load of about $40 \mathrm{~m} / \mathrm{s}$, snow load of $20 \mathrm{psf}$, water depth of $50 \mathrm{~m}$, water level variation of $10 \mathrm{~m}$, and swell height of $1 \mathrm{~m}$ ). We estimate an installed system cost premium of $\$ 0.26 / \mathrm{W}_{\mathrm{DC}}(25 \%)$ for $10-\mathrm{MW}_{\mathrm{DC}}$ fixed-tilt FPV systems, compared with ground-mounted, fixed-tilt PV installed over bare ground. Higher structural costs related to the floats and anchoring system are the largest contributors to this premium. Currently, site investigation costs are also higher for FPV because of the additional effort needed to plan and design these more complex installations. Our preliminary sensitivity analysis shows that the installed cost of FPV systems is most sensitive to float costs, wind and snow loading, and module efficiency. FPV deployment is in an early stage, and additional experience, best practice development, and new configurations and technologies could help reduce the costs of FPV systems over time.

Our analysis does not capture the potential value proposition of FPV systems in detail. However, our analysis based on the limited currently available data suggests that the levelized cost of energy (LCOE) from FPV systems is around 20\% higher than the LCOE from ground-mounted PV systems (excluding the solar Investment Tax Credit). Lifetime analysis of costs and revenues - encompassing the impacts of PV system design and the energy-water nexus - is required to understand the complete economic feasibility of FPV applications. As the necessary data become available, we plan to incorporate more detailed cost-benefit analysis into our FPV modeling. 


\section{Table of Contents}

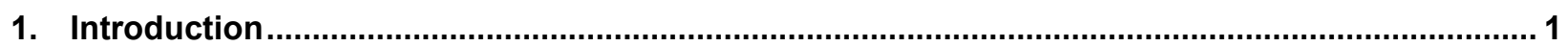

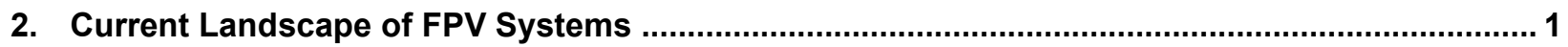

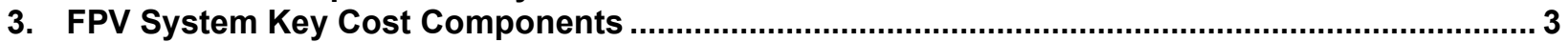

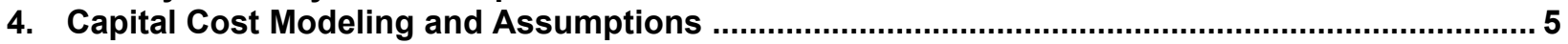

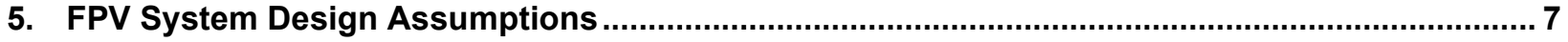

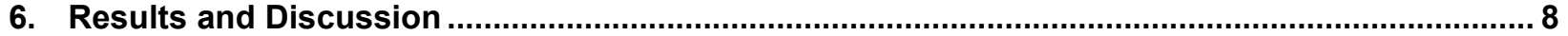

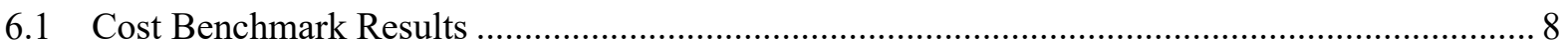

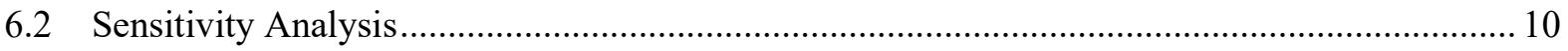

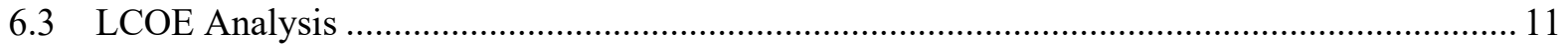

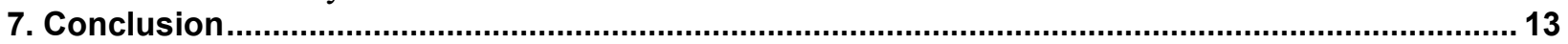

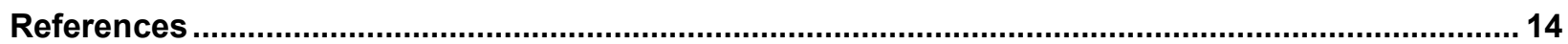




\section{List of Figures}

Figure 1. Annual global FPV capacity, 2017-2020 (Cox 2021) .......................................................... 2

Figure 2. Global FPV market shares by installed capacity (Cox 2021) .................................................. 2

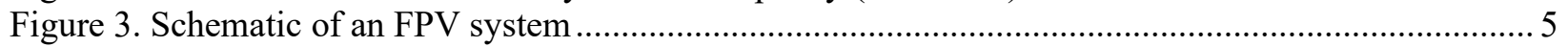

Figure 4. U.S. installed costs of 10-MW $\mathrm{DC}$ base-scenario FPV system and ground-mounted PV system.... 9

Figure 5. Benchmark cost of base-scenario FPV system with varying system sizes.............................. 10

Figure 6. Sensitivity of FPV installed system cost to varying input assumptions ................................... 11

Figure 7. Simple LCOE comparison between ground-mounted PV and FPV systems ........................... 13

\section{List of Tables}

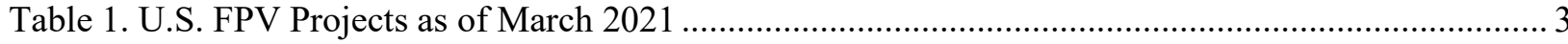

Table 2. Key Differences Between Ground-Mounted PV and FPV .................................................... 7

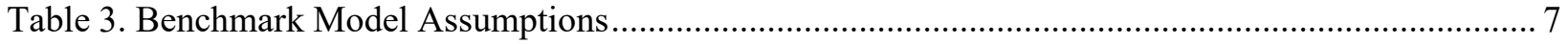

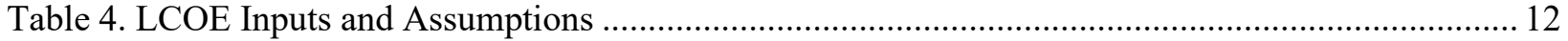




\section{Introduction}

With the rapidly declining cost of solar photovoltaics (PV), system installers worldwide are exploring ways to integrate more PV into power systems. In the United States, PV generation has grown rapidly during the past decade (U.S. Energy Information Administration 2020) and is expected to grow swiftly over the next couple of decades (U.S. Department of Energy [DOE] 2021). However, the growth of ground-mounted PV installations could put pressure on land use, particularly in locations where land is relatively scarce and expensive. Floating PV (FPV) is one solution that is gaining traction. The global capacity of FPV systems grew from less than 1 MW DC in 2007 to approximately $2.6 \mathrm{GW}_{\mathrm{DC}}$ in 2020 (Cox 2021).

FPV offers multiple benefits. It eliminates competition for land that could be used for other purposes, such as agriculture or urban development. In the United States, it has been estimated that approximately 2.1 million ha of FPV could be installed on existing bodies of water (Spencer et al. 2019). The watercooling effect inherent to FPV systems increases PV efficiency and energy yield compared to groundmounted systems, particularly in hot regions. Where there is surplus water, cooling can be enhanced via water sprinklers with low power consumption. Other potential FPV benefits include reduced module shading, reduced evaporation from water bodies, and reduced algal growth (Gadzanku et al. 2021b). In addition, FPV and hydropower can operate as a hybrid system to provide firm and dispatchable power and reduce transmission and interconnection costs (Lee et al. 2020).

FPV could entail environmental impacts as well. It could affect aquatic life, hinder recreational activities, and create biofouling, particularly in freshwater lakes, although such impacts have yet to be researched in detail. Some reports suggests that FPV could disturb aquatic life by blocking sunlight from reaching the water surface, but the results are not conclusive (Hooper et al. 2021).

There is currently limited publicly available data about the capital costs or operations and maintenance (O\&M) costs of FPV systems. Thus, we gathered data from multiple FPV industry firms to benchmark the capital costs of FPV installed on artificial water bodies. We use a modified version of the National Renewable Energy Laboratory's (NREL's) bottom-up installed cost model (Feldman et al. 2021). First, we discuss current market conditions and provide an overview of FPV system components. Next, we describe our modeling assumptions. In the results, we analyze capital costs for a benchmark FPV design compared with conventional ground-mounted PV systems, use a sensitivity analysis to account for variable system design parameters (snow load, wind load, water depth, swell, and water level variation), and compare the levelized cost of energy (LCOE) for FPV and ground-mounted PV systems.

\section{Current Landscape of FPV Systems}

Global FPV deployment increased substantially over the past decade (Figure 1). In 2020, cumulative global capacity reached approximately $2.6 \mathrm{GW}$, with most of this capacity installed in China, Taiwan Region, and Japan (Cox 2021). China hosts about 52\% of global FPV capacity (Cox 2021). Figure 2 shows global FPV market shares by installed capacity. Land scarcity, aggressive renewable energy targets, falling PV costs, and targeted subsidies have contributed to the rapid FPV growth across Asia (Gadzanku et al. 2021a). Asia is expected to continue leading in FPV deployment, followed by European countries with scarce land resources (International Renewable Energy Agency [IRENA] 2019). Recently published best practices guide for designing and installing FPV projects might encourage further FPV deployment (DNV GL 2021). 
Based on data provided by installers, FPV systems ranged in capacity from 1-100 MW 2020. Globally, most existing FPV installations have capacities below $5 \mathrm{MW}_{\mathrm{DC}}$, but systems with capacities greater than $10 \mathrm{MW}$ DC have proliferated since 2017.

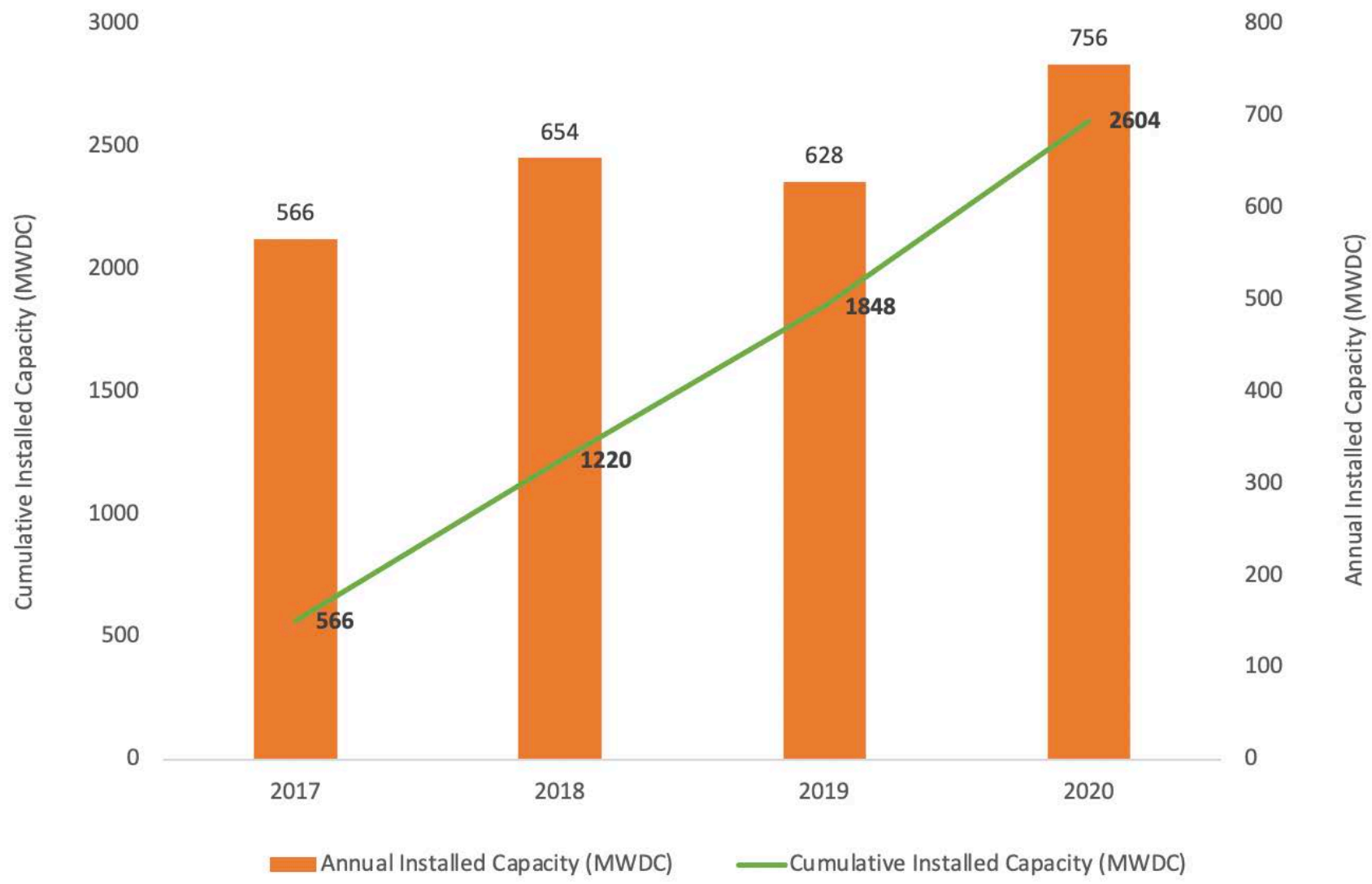

Figure 1. Annual global FPV capacity, 2017-2020 (Cox 2021)

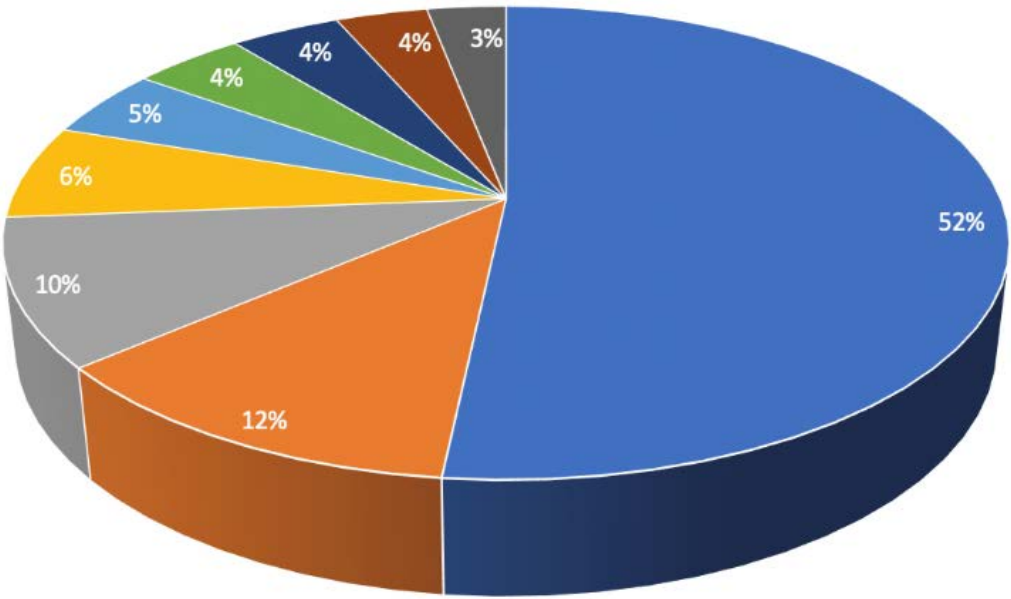

- China = Taiwan Region = Japan = Vietnam = South Korea = Netherlands = Israel " India " Rest of World

Figure 2. Global FPV market shares by installed capacity (Cox 2021) 
The United States had only two FPV projects before 2016. However, by the end of 2020, more than 20 U.S.-based FPV installations had a cumulative capacity of approximately $12 \mathrm{MW}_{\mathrm{DC}}$ (Cox 2021). The relative abundance of land and lack of FPV incentives in the United States has slowed FPV growth compared with the growth in some Asian countries. Although the range of installed capacity of U.S. FPV systems is $100 \mathrm{~kW}_{\mathrm{DC}}-5 \mathrm{MW}$ DC, in this report we benchmark a $10 \mathrm{MW}_{\mathrm{DC}}$ system which represents the expected typical size of FPV systems to be installed over the next couple of years based on our discussions with project developers. Table 1 lists U.S. FPV installed projects, with project size greater than $100 \mathrm{~kW}$ DC, we could find data on as of March 2021.

Table 1. U.S. FPV Projects as of March 2021

\begin{tabular}{lc}
\hline Location & MW $_{\text {DC }}$ \\
\hline Healdsburg, California & 4.78 \\
Sayreville, New Jersey & 4.40 \\
Windsor, California & 1.78 \\
Gidding, Texas & 0.99 \\
Altamonte Springs, Florida & 0.96 \\
Dixon, California & 0.61 \\
Kelseyville, California & 0.25 \\
Orlando, Florida & 0.25 \\
Miami Airport, Florida & 0.15 \\
Orlando Airport, Florida & 0.13 \\
\hline
\end{tabular}

\section{FPV System Key Cost Components}

FPV systems can be installed on various artificial or natural water bodies. Typically, FPV systems have been installed on artificial water bodies such as industrial ponds, hydropower reservoirs, agricultural ponds, and flood control reservoirs. FPV systems can also be installed in the ocean. Depending on the site specifics, the type of floating structure and anchoring solution varies, which ultimately affects the total system cost. Figure 3 shows an FPV system schematic. The following are key system cost items:

- Site staging: FPV systems require detailed analysis of wave speed and other aspects of waves through a hydrodynamic survey. Also necessary are a study of water depth and water level variation via a bathymetry survey and a geotechnical study to assess soil conditions in the basin. These studies add costs compared with land-based systems. The total cost for site staging depends on the type of water body and the area that must be surveyed.

\section{- Structural balance of system (SBOS)}

- Floats: In FPV systems, a floating structure supports the PV modules, which are usually mounted at a fixed tilt. Different types of floats using different materials and configurations are available, but in this report, we focus only on floats designed for use in artificial water body FPV installations. Such floats are usually made of high-density polyethylene (HDPE). They are typically cheaper than floats that use pontoons and have fewer metal parts. These HDPE floats are easy to assemble and install; when correctly 
deployed, they adapt to wave motion and reduce mechanical load on the entire support structure. All the floats are connected by pins or bolts. Apart from the main floats directly attached to the modules, secondary floats provide additional buoyancy and serve as a walkway for inspections and maintenance. This HDPE floating structure simplifies assembly and deployment of the modules compared to installing modules on a pile-driven structure. The tilt angle is adjusted depending on how windy the site is. Tilt angles are normally lower compared to angles on typical ground-mounted PV systems to limit wind effects. In contrast to ground-mounted systems, site preparation activities such as soil stripping, grading, and compacting using heavy equipment or removal of existing vegetation are not required for FPV installation in most cases. There may be limited ground disturbance during installation of onshore components such as inverters and piledriven anchors.

$\circ$ Anchoring and mooring: The FPV system is held in place by an anchoring and mooring system, which minimizes lateral movement and rotation and thus the risk of collision with the shore or floating objects. Depending on the water profile and soil condition in the basin, the project developer can choose between bottom anchoring and bank anchoring. Bottom anchoring was more common in the past, but our recent interviews suggest that pile-driven anchors on the banks are becoming popular for inland and artificial water bodies. Bank anchoring is often the most cost-effective option. The type and quantity of mooring lines must be selected to account for ambient stresses and variations in water level. Failed mooring could lead to catastrophic failure of FPV projects. In our analysis, we assume projects use elastic mooring, which is preferred by many of the installers we interviewed because it extends the longevity of FPV projects.

O Other: Other SBOS components include PV module clips, screws, connectors, and the foundation for electrical equipment installed on shore.

- Electrical components: Junction boxes and electric cables that are well established for marine and freshwater environments connect modules on the floating array. The connected wires run to shore using marine-grade submersible cables. We assume use of a central inverter installed on the shore, which is a comparatively low-cost solution and typical for most installations on artificial water bodies. String or central inverters can be installed on floats, but the additional floats may add significant expense. We assume other required electrical equipment (e.g., transformers, voltage regulators) are installed on the shore.

- Soft costs: Soft costs include permitting, inspection, and interconnection; sales tax; shipping and handling; contingency; developer overhead; engineering, procurement, and construction (EPC) overhead, and profit markup.

Because FPV plants are not stationary, it is necessary to calculate environmental loads in conjunction with the equation of motion of the entire support structure. However, we do not model in detail factors such as the impact of the spatial and temporal distribution of wind on mooring line requirements, the impact of wind and snow load across all modules, and the effect of temporal and spatial characteristics of wave and current loads on the FPV structure. Rather, we approximate the related cost impacts using mean values derived from FPV site and cost data provided by system installers. Accurate estimation of FPV system design and installation practices would require in-depth numerical and physical modeling. In addition, estimates would vary widely by site and system design. For this reason, we conduct a sensitivity analysis of site-related input variables to illustrate potential variations in FPV system cost. 


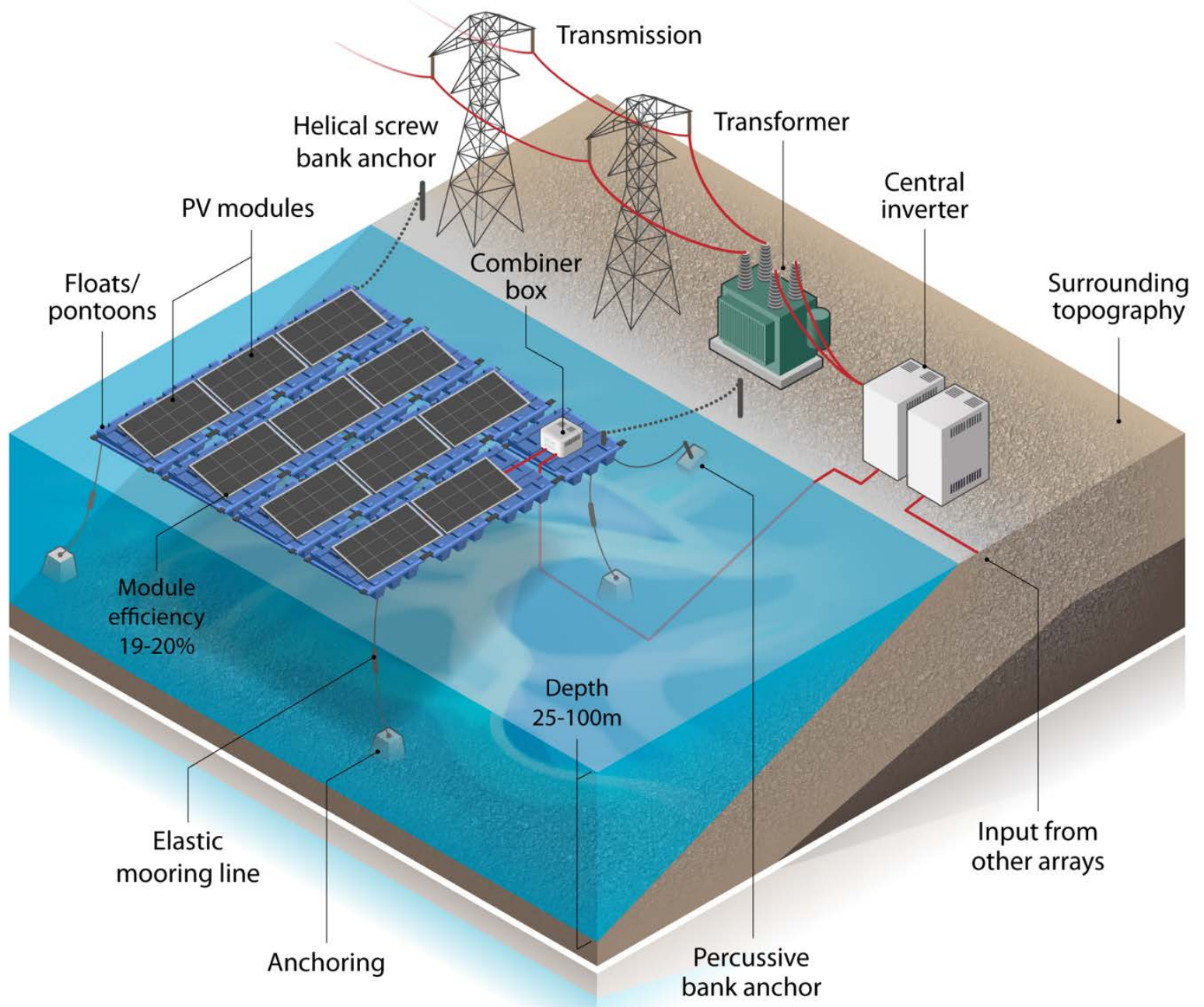

Figure 3. Schematic of an FPV system

Image credit: Alfred Hicks, NREL

\section{Capital Cost Modeling and Assumptions}

We use NREL's bottom-up modeling method to calculate the capital costs associated with FPV application for different site characteristics and system design types. This approach involves mapping all key steps in the installation process and determining the labor, materials, and equipment required for each step. We also add overhead costs and profit. However, project financing costs are not included in the upfront system cost estimates. This method is detailed for conventional ground-mounted PV systems in NREL's annual PV system cost benchmark report (Feldman et al. 2021). We modify the conventional model to reflect the differences in FPV system assumptions documented in Table 2. Our results use U.S. cost assumptions for labor (Bureau of Labor Statistics 2021).

We assume that the number of primary floats required is equal to twice the number of modules under average site conditions (wind load of $40 \mathrm{~m} / \mathrm{s}$, snow load of $20 \mathrm{psf}$ ). If the site has higher snow or wind 
load, we assume more floats are installed between panels to add stability; locations with higher snow or wind load are assumed to have more floats by a factor that depends on the difference between the average load value and actual load value. For instance, if a site's wind load is twice the average wind load, the model assumes $15 \%$ extra primary floats, and if the wind load is three times the average wind load, the model assumes 50\% extra primary floats. Similarly, the model assumes $17 \%$ and $47 \%$ extra primary floats for regions with snow load twice the average snow load and thrice the average snow load, respectively, based on data provided by FPV developers. The average number of secondary floats required is assumed to be equal to $20 \%$ of the total number of primary floats; when wind or snow loads are less than average load values, the number of secondary floats required is reduced. We assume that installing a PV module over a pair of floats takes 15 minutes in total with the help of two laborers, which is roughly one-fourth the time required to install horizontal torque tubes and vertical columns for ground-mounted PV systems. We assume the same types of modules and inverters are used in groundmounted PV and FPV installations.

External factors such as wind, snow, waves, water current, and water level variation determine the quantity of anchoring and mooring required. Because quantifying anchoring and mooring is complex and highly variable by project location, we use a set of simplified assumptions based on the mean value of different site characteristics and structural requirements from a dataset of several installed and potential FPV projects vetted by ISI Floating Systems. We assume 20 shore anchors per MW for projects with system capacity less than $30 \mathrm{MW}$ and 15 shore anchors per MW for projects greater than or equal to $30 \mathrm{MW}$. We assume every $\mathrm{MW}$ installed requires 30 elastic mooring lines, with additional lines required for high-wind sites. The model assumes the number of mooring lines required increases by a factor equal to the percentage of additional primary floats required for sites with higher wind speeds.

Transmission costs could vary depending on the distance between distribution and transmission lines, type of transmission line, type of terrain, and transmission capacity. However, we do not include any transmission cost. The cost of distribution equipment is modeled to be higher for higher $\mathrm{kVA}$ and $\mathrm{kV}$ ratings, and system voltage affects wiring and combiner box costs. For instance, a 1,500- $\mathrm{V}_{\mathrm{DC}}$ system requires fewer combiner boxes and less wiring compared to a $1,000-\mathrm{V}_{\mathrm{DC}}$ system. We estimate interconnection costs based on the average cost per $\mathrm{MW}_{\mathrm{AC}}$ for a given project size class as detailed in Bird et al. (2018). We use a fixed average permitting cost based on the approach detailed in Feldman et al. (2021).

In our benchmark we model FPV systems with central inverters placed on land. Electrical equipment selected for FPV installations must have a high Ingress Protection (IP) rating to avoid damage due to dust and water, because the system usually experiences high humidity and wave motion.

Our input data come mainly from interviews with personnel from different FPV developers and installers: ISI Floating Systems, Ciel et Terre, D3Energy, Seaflex, Multiconsult, Innosea, Baywa, and Noria Energy. We supplement the interview data (float cost and anchoring and mooring cost) with unit cost data from standard construction cost guides (Gordian 2021). FPV balance of system cost are based on a simple average of material, equipment, and labor cost across all U.S. states and site related metrics inferred from the FPV projects dataset provided by system installers. 
Table 2. Key Differences Between Ground-Mounted PV and FPV

\begin{tabular}{|c|c|c|}
\hline & Ground-Mounted PV & FPV \\
\hline PV Module Support Structure & Racking structure using steel & Floats predominantly made of $\mathrm{HDPE}$ \\
\hline Wiring & Regular & Waterproof and marine grade \\
\hline Stability & $\begin{array}{l}\text { Pile driven plus concrete } \\
\text { foundation }\end{array}$ & $\begin{array}{l}\text { Bank or bottom anchoring with } \\
\text { mooring lines }\end{array}$ \\
\hline Site Preparation & $\begin{array}{l}\text { Geotechnical investigation, ground } \\
\text { leveling and grading }\end{array}$ & $\begin{array}{l}\text { Geotechnical investigation, } \\
\text { hydrodynamic survey, bathymetry } \\
\text { study }\end{array}$ \\
\hline External Loading Factors & Wind and snow & $\begin{array}{l}\text { Wind, snow, waves, water currents, } \\
\text { water depth, water level variation }\end{array}$ \\
\hline Tilt Angle & $33^{\circ}$ & $10^{\circ}$ \\
\hline Levelized O\&M (\$/kW-yr) ${ }^{1}$ & 18 & 15.5 \\
\hline IP Rating & Lower than IP66 & Greater than IP67 \\
\hline $\begin{array}{l}\text { Sales Tax, Shipping \& } \\
\text { Handling, Contingency }\end{array}$ & $5 \%, 0 \%, 3 \%$ & $5 \%, 5 \%, 5 \%$ \\
\hline $\begin{array}{l}\text { Developer Overhead, EPC } \\
\text { Overhead, Net Profit }\end{array}$ & $7.7 \%, 10.9 \%, 7.84 \%$ & $7.7 \%, 10.9 \%, 7.84 \%$ \\
\hline
\end{tabular}

\section{FPV System Design Assumptions}

Table 3 shows the FPV system design assumptions for our base case benchmark scenario. These assumptions are based on median values provided by FPV developers and installers. Because these parameters vary depending on the needs of specific projects, we provide sensitivity analysis results in Section 6.2.

Table 3. Benchmark Model Assumptions

\begin{tabular}{lc}
\hline Category & Modeled Value \\
\hline Module Efficiency $(\%)$ & $19.9 \%$ \\
\hline Float Cost $\$ / W_{D C}$ & $\$ 0.30$ \\
Snow Load $(\mathrm{psf})$ & 20 \\
Wind Load $(\mathrm{m} / \mathrm{s})$ & 38.85 \\
Water Depth $(\mathrm{m})$ & 50 \\
Water Level Variation $(\mathrm{m})$ & 10 \\
Swell Height $(\mathrm{m})$ & 1 \\
\hline
\end{tabular}

\footnotetext{
${ }^{1}$ Some FPV installers claim fewer O\&M occurrences per year due to lack of vegetation and fencing maintenance, leading to O\&M savings. However, others say O\&M costs are comparable to costs for ground-mounted PV systems, with activities requiring boats to access floating panels away from shore and divers needed to perform preventive maintenance of anchors and mooring lines. In our analysis we assume the FPV O\&M cost is equal to the ground-mounted PV O\&M cost minus the land leasing cost.
} 
Wind and snow loads are extremely important in evaluating system strength and reliability. These loads on the modules are transmitted to the floating structure, and the stress at connection points increases with higher wind and snow loads added to the PV module weight. Also, the optimal orientation and tilt angle of PV panels and mooring system design are determined by wind direction, wind load, and snow load. In our model, increasing the wind and snow loads increases the quantity of floats and mooring lines required per module. The quantity of anchors required is determined by factors such as water depth, water level variation, and swell height.

\section{Results and Discussion}

This section presents the results of our benchmark and sensitivity analyses. It also presents a high-level comparison of ground-mounted PV and FPV LCOE.

\subsection{Cost Benchmark Results}

Figure 4 compares the U.S. installed costs of a benchmark ground-mounted PV system versus our basescenario FPV system, assuming system capacities of $10 \mathrm{MW}_{\text {DC. The FPV system has a higher installed }}$ cost, $\$ 0.26 / \mathrm{W}_{\mathrm{DC}}(25 \%)$ greater than the cost per $\mathrm{W}_{\mathrm{DC}}$ of ground-mounted PV system, largely owing to much higher structural costs (around 300\%) related to the floats and anchoring system. Optimizing the number of floats to match anticipated environmental loads may help reduce float costs. Conversely, tailoring FPV system designs to installation sites may increase costs related to upfront engineering and feasibility studies, compared with the costs of ground-mounted systems with standardized designs.

The FPV system cost model assumes a higher contingency rate (5\% versus $3 \%$ for the ground-mounted system) due to its relative newness and an extra shipping and handling cost of 5\% for the floats and anchoring system. Installation labor and equipment costs are 50\% lower for the FPV system-because high-power installation equipment is used less, and float assembly is relatively easy and fast—which partially offsets the FPV system cost premium. Site staging costs are included under electrical balance of system cost category for ground mount systems. Site staging includes access roads and parking, and security fencing which are not included in floating PV system cost modeling. Hence, the electrical BOS for floating PV is slightly lower. 
$\$ / W D C 2020$ USD

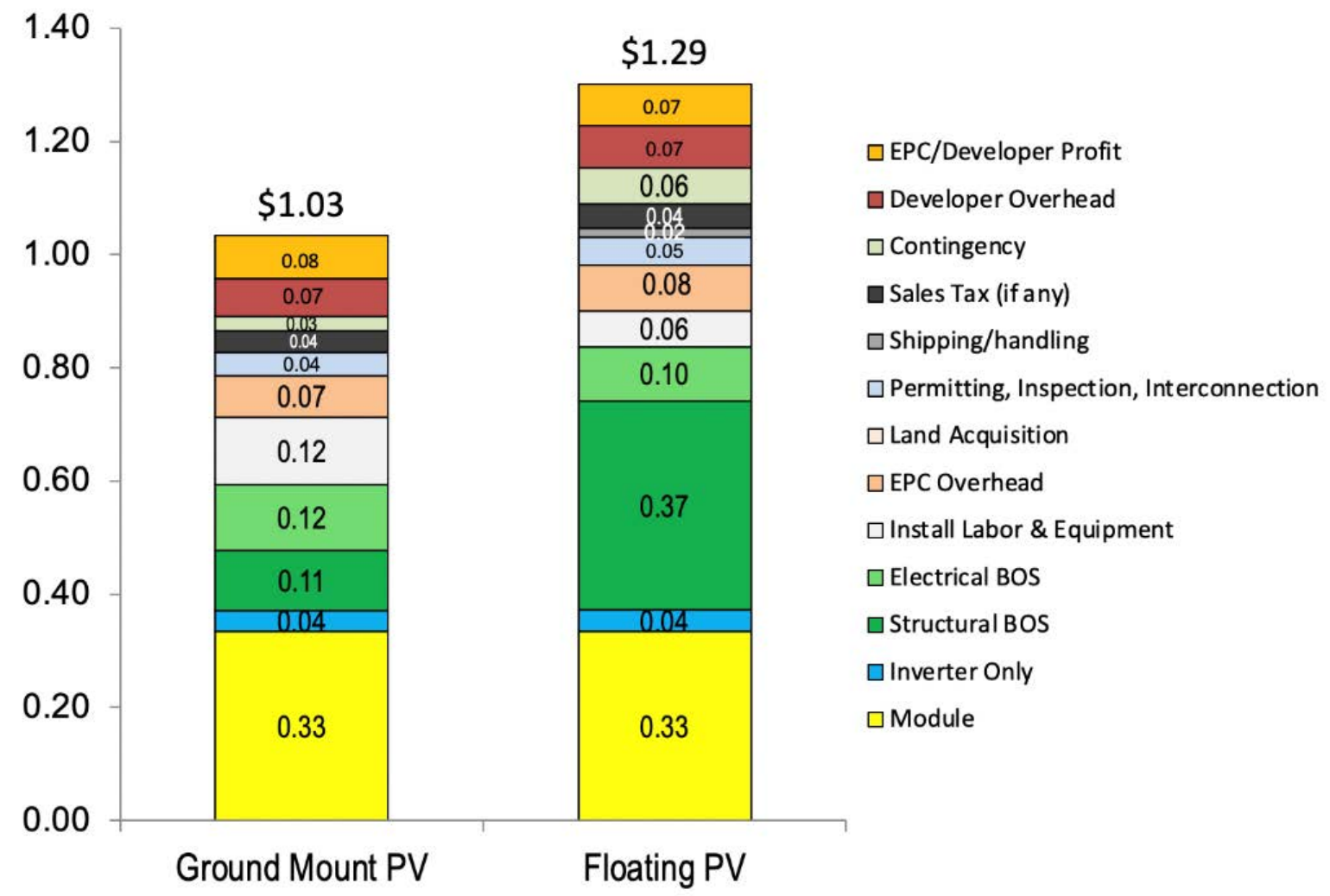

Figure 4. U.S. installed costs of 10-MWDC base-scenario FPV system and ground-mounted PV system

Figure 5 shows the decreasing per-watt cost of the base-scenario FPV system with increasing system size. The economies of scale are mainly driven by SBOS costs, which contribute $25 \%-30 \%$ of the total cost, depending on system size. Approximately $75 \%-85 \%$ of the SBOS cost can be attributed to float costs. The average cost of floats produced in the United States is $\$ 0.20-\$ 0.40 / \mathrm{W}_{\mathrm{DC}}$, and the average cost of floats produced in Europe including shipping to the United States is estimated to be between $\$ 0.22 / \mathrm{W}_{\mathrm{DC}}$ and $\$ 0.90 / \mathrm{W}_{\mathrm{DC}}$, depending on the type of HDPE floating structure and quantity purchased. The per unit cost of floats decline with increasing quantity of floats purchased. For example, $\$ 0.40 / \mathrm{W}_{\mathrm{DC}}$ for a 2-MW FPV system, $\$ 0.36 / \mathrm{W}_{\mathrm{DC}}$ for a 5 -MW FPV system, $\$ 0.30 / \mathrm{W}_{\mathrm{DC}}$ for a $10-\mathrm{MW}$ FPV system, and $\$ 0.20 / \mathrm{W}_{\mathrm{DC}}$ for a $50-\mathrm{MW}$ FPV system. The cost of float for a given system size assumes that the installer only orders floats for one system at a time. A developer large enough to deploy multiple systems in parallel could purchase floats at the lower cost corresponding to the increased volume. 
$\$ /$ WDC 2020 USD

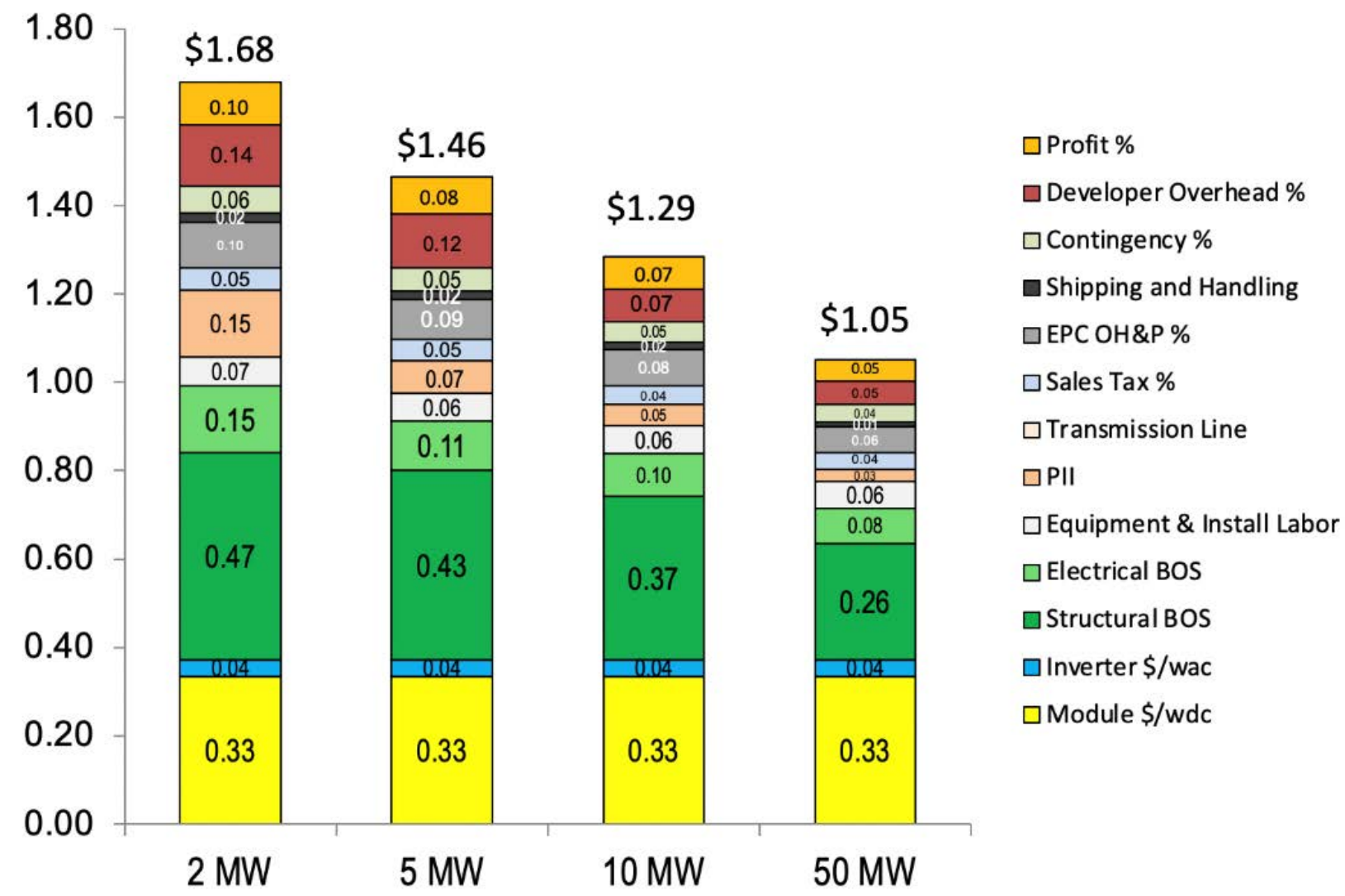

Figure 5. Benchmark cost of base-scenario FPV system with varying system sizes

\subsection{Sensitivity Analysis}

The novelty of FPV applications adds uncertainty to our input assumptions, and our benchmark scenario does not capture all the variability among projects in terms of structural design, site requirements, and other factors; this variability is expected to be much larger than the variability for traditional PV applications. Figure 6 shows the sensitivity of FPV system installed cost to different input parameters. FPV systems are most sensitive to float costs, wind, and snow loading (which affects the number of floats required), and module efficiency ${ }^{2}$. Water level variation and water depth have a similar impact on the cost. Swell has much smaller impact for the range of values assumed for inland water bodies. However, these factors may have larger impacts if site conditions and/or system designs differ substantially from our assumptions.

\footnotetext{
${ }^{2}$ In our FPV system cost model, power is assumed to be fixed and area is not constrained. Hence, system capacity remains the same as module efficiency varies.
} 


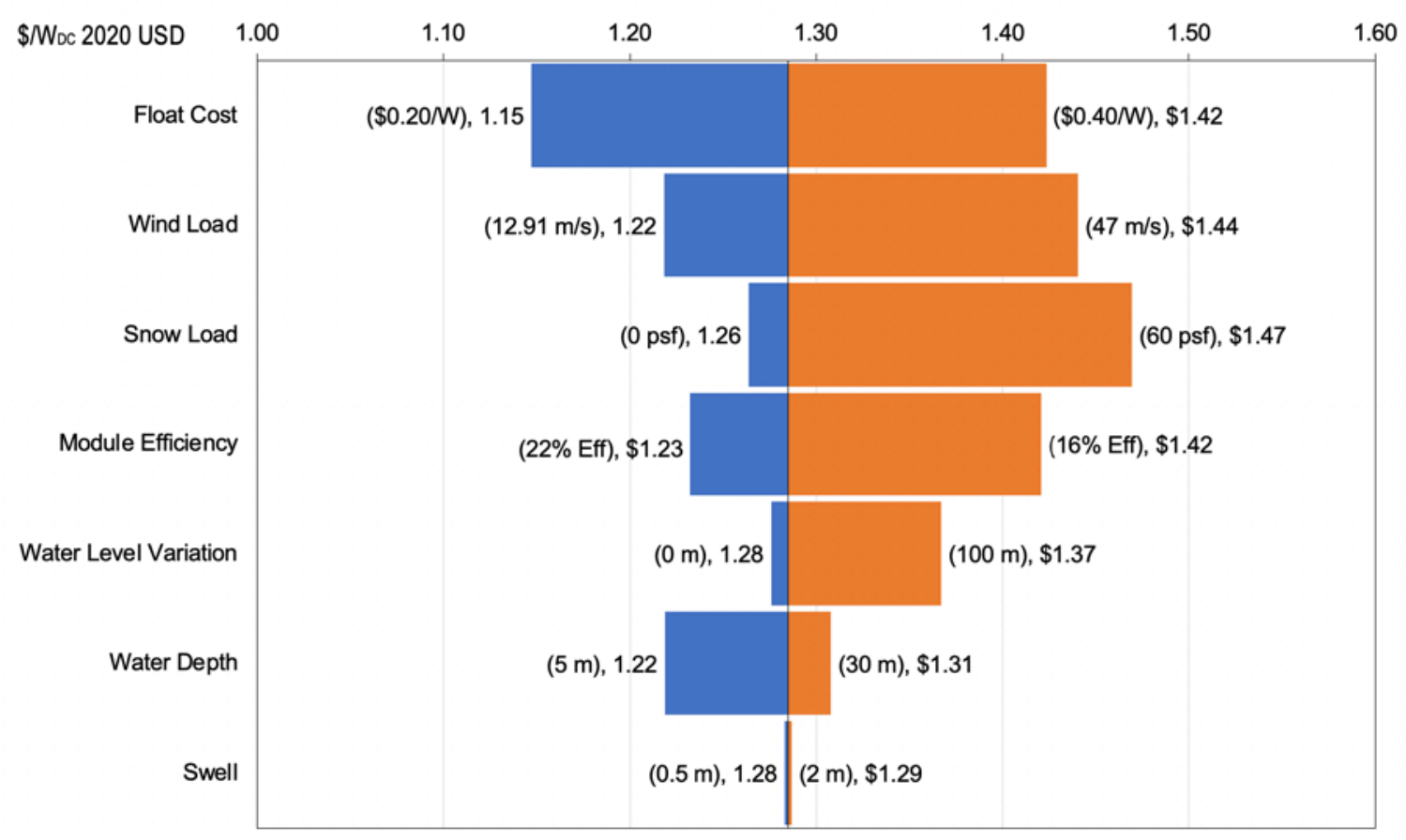

Figure 6. Sensitivity of FPV installed system cost to varying input assumptions

\subsection{LCOE Analysis}

Many factors influence the LCOE of an FPV system, including albedo, ambient temperature, module operating temperature, heat loss factor, soiling and mismatch losses, tilt angle, ground coverage ratio, and environmental loads. Because NREL's System Advisor Model and the PVsyst model do not include an option explicitly to model FPV systems yet, we carry out a simplified LCOE analysis using the following formula.

$$
L C O E=\frac{E+\frac{F^{n}}{(1+R)^{n}}-\sum_{n-1}^{N} \frac{(D+D F)^{n}}{(1+R n)^{n}} \times(T)+\sum_{n-1}^{N} \frac{(O+I)^{n}}{(1+R n)^{n}} \times(1-T)-\frac{R v^{n}}{(1+R)^{n}} \times(1-T)+\sum_{n-1}^{N} \frac{(P)^{n}}{(1+R n)^{n}} \times(1-T)}{\left(\sum_{n-1}^{N} \frac{\operatorname{Pr} \times(1-D r)^{n}}{(1+R)^{n}}\right) \times(1-T)}
$$

$E=$ Initial equity investment of solar

$I=$ Debt interest payments

$P=$ Debt principal payments

$F=$ Follow-on investments (inverter replacements) $)^{3}$

$D=$ Depreciation of solar (which may include depreciation from follow-on investments)

$R=$ Real discount rate

$R n=$ Nominal discount rate

$T=$ Tax rate

$O=$ Annual O\&M (nominal)

$D r=$ Degradation rate of $\mathrm{PV}$

$R v=$ Residual value

$P r=$ Initial annual system production

\footnotetext{
${ }^{3}$ After 10 years, failure of central inverter components could reduce capacity. We assume $20 \%$ of inverter capacity is restored via inverter replacement. We assume costs for inverters will drop 20\% in the next 10 years (Walker 2020).
} 
Table 4 shows the assumptions for our LCOE analysis. Limited system installations in U.S. and lack of publicly available data add uncertainty to estimates of FPV lifetime and financial assumptions, and so we assume the FPV and ground-mounted PV financial assumptions to be the same.

Table 4. LCOE Inputs and Assumptions

\begin{tabular}{|c|c|c|}
\hline Model Component & Ground-Mounted PV & FPV \\
\hline System size ${ }^{4}$ & $10 \mathrm{MW}$ & $10 \mathrm{MW}$ \\
\hline Initial investment & $\$ 10.3$ million & $\$ 12.9$ million \\
\hline $\begin{array}{l}\text { Follow-on investments (inverter } \\
\text { replacement after year 10) }\end{array}$ & $\$ 80,000$ & $\$ 80,000$ \\
\hline $\begin{array}{l}\text { Real discount rate (Walker et al. } \\
\text { 2020) }\end{array}$ & $5.1 \%$ & $5.1 \%$ \\
\hline Debt fraction & $71.8 \%$ & $71.8 \%$ \\
\hline Residual value & $\$ 0$ & $\$ 0$ \\
\hline $\begin{array}{l}\text { Annual energy yield, Kansas }{ }^{5} \\
\left(k W h / k W_{D C}\right)\end{array}$ & 1,570 & $\begin{array}{l}1,527 \text { (includes } 3 \% \text { gain due to }^{\text {cooling effect) }}{ }^{6}\end{array}$ \\
\hline Debt term & 18 years & 18 years \\
\hline Debt interest rate & $5 \%$ & $5 \%$ \\
\hline Analysis period & 30 years & 30 years \\
\hline Tax rate & $25.74 \%$ & $25.74 \%$ \\
\hline Levelized O\&M (\$/kW/yr) & $\$ 18$ & $\$ 15.5$ \\
\hline Annual PV degradation & $0.70 \%$ & $0.70 \%^{7}$ \\
\hline System lifetime & 30 years & 30 years \\
\hline Inflation & $2.5 \%$ & $2.5 \%$ \\
\hline $\begin{array}{l}\text { LCOE \$/MWh (without solar } \\
\text { Investment Tax Credit [ITC]) }\end{array}$ & $\$ 47.1$ & $\$ 56.6$ \\
\hline $\begin{array}{l}\text { LCOE \$/MWh (with solar } \\
\left.\text { Investment Tax Credit [ITC }{ }^{8}\right] \text { ) }\end{array}$ & $\$ 32.4$ & $\$ 37.8$ \\
\hline
\end{tabular}

${ }^{4}$ Assuming an inverter loading ratio of 1.3 .

${ }^{5}$ The medium solar resource location is Fredonia, KS, which is near the geographic center of the 48 contiguous states and corresponds with the area-weighted capacity factor of the 48 contiguous states as outlined in the 2021 NREL Annual Technology Baseline (NREL 2021).

${ }^{6}$ The initial energy yield of FPV systems is estimated to be $1,483 \mathrm{kWh} / \mathrm{kW}$, which is $5 \%$ lower than the initial energy yield of ground-mount PV systems because of the difference in panel tilt angle. The energy gain from the cooling of FPV systems is estimated to be between 3\% in the Netherlands and 6\% in Singapore (Dörenkämper et al. 2021). Because no comprehensive data are available on FPV energy yield improvements in the United States, we assume the conservative 3\% value.

${ }^{7}$ While one study reports a slightly elevated degradation for a module in an FPV test configuration (Goswami and Sadhu 2021) this study was only for 17 months with a single module test system. Given the lack of long-term field data from systems at scale we assume the same degradation rate for both ground mount and floating PV modules.

${ }^{8}$ We assume $26 \%$ ITC for projects starting construction in 2021. 
Figure 7 shows our LCOE results. For FPV systems, the LCOE is around $\$ 57 / \mathrm{MWh}$ without the ITC and $\$ 38 / \mathrm{MWh}$ with the ITC. For ground-mounted PV systems, the LCOE is around $\$ 47 / \mathrm{MWh}$ without the ITC and \$32/MWh with the ITC. Despite the increased energy yield due to cooling effects of FPV systems and lower O\&M assumptions, their LCOE is still $20 \%$ higher without the ITC and $17 \%$ higher with the ITC, compared with the LCOE of ground-mounted systems.

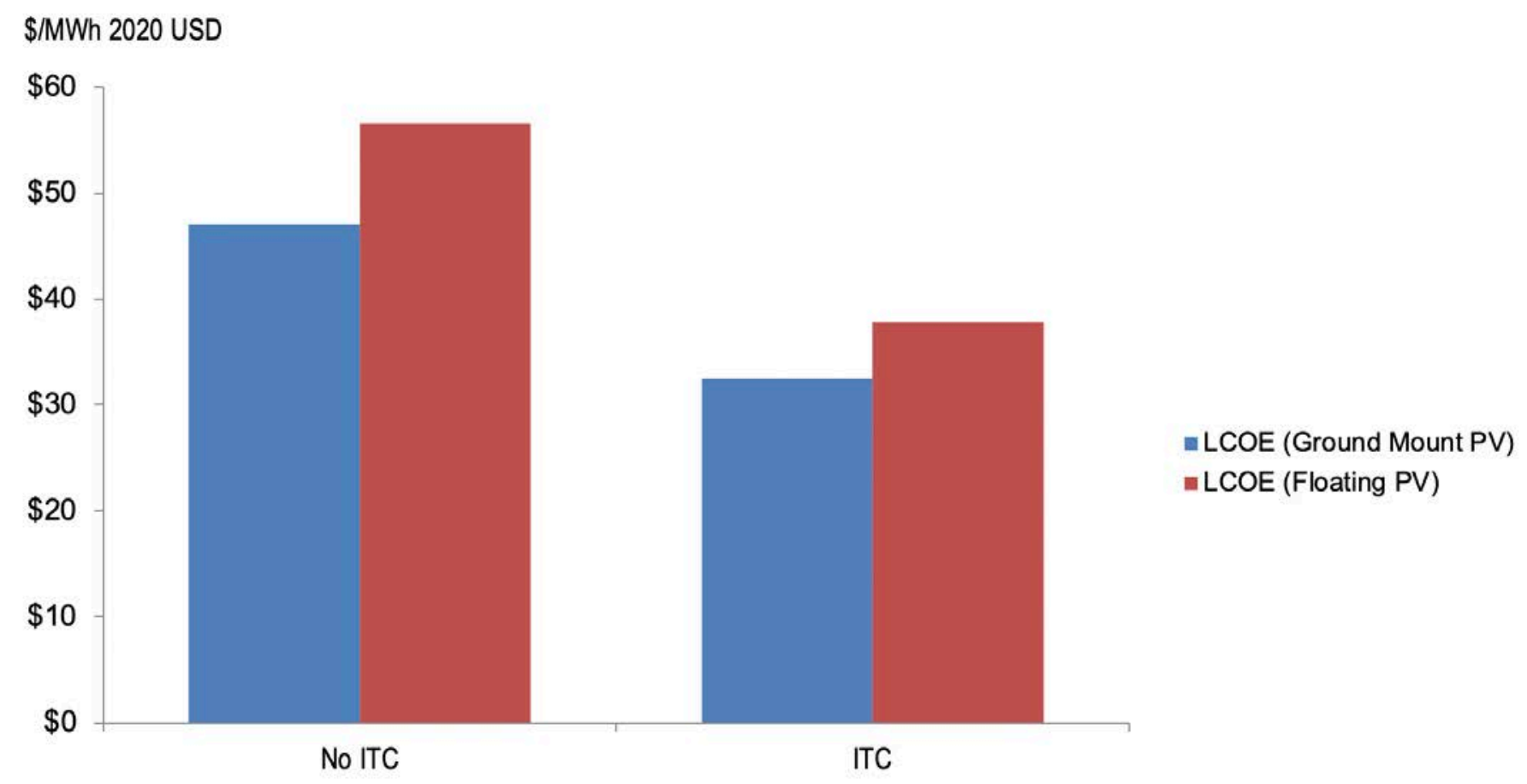

Figure 7. Simple LCOE comparison between ground-mounted PV and FPV systems

\section{Conclusion}

Based on our bottom-up cost model, we estimate an installed system capital cost premium of $\$ 0.26 / \mathrm{W}_{\mathrm{DC}}$ (25\%) for $10-\mathrm{MW}_{\mathrm{DC}} \mathrm{FPV}$ systems, compared with conventional ground-mounted PV installed over bare ground. Higher structural costs related to the floats and anchoring system are the largest contributors to this premium. Site investigation costs are also higher for FPV because of the additional effort needed to plan and design these more complex installations. Our sensitivity analysis shows that the installed cost of FPV systems is most sensitive to float costs, wind and snow loading, and module efficiency. FPV deployment is in an early stage, and additional experience, best practice development, and new configurations and technologies might help reduce the costs of FPV systems over time.

Our analysis does not capture the full value proposition of FPV systems in detail. However, our simplified analysis based on currently available data suggests that the LCOE from FPV systems is around $20 \%$ higher than the LCOE from ground-mounted PV systems without the ITC. Lifetime analysis of costs and revenues - encompassing the impacts of PV system design and the energy-water nexus - is required to understand the complete economic feasibility of FPV applications. As the necessary data become available, we plan to incorporate detailed cost-benefit analysis into our FPV modeling. 


\section{References}

Bird, Lori, Francisco Flores, Christina Volpi, and Kristen Ardani. 2018. Review of Interconnection Practices and Costs in the Western States. Golden, CO: National Renewable Energy Laboratory. https://www.nrel.gov/docs/fy18osti/71232.pdf.

Bureau of Labor Statistics. 2021. "National Occupational Employment and Wage Estimates United States." Accessed September 14, 2021. https://www.bls.gov/oes/.

Cox, Molly. 2021. Floating Solar Landscape 2021. United States: Wood Mackenzie. https://www.woodmac.com/reports/power-markets-floating-solar-landscape-2021-476537.

DNV GL. 2021. Design, development and operation of floating solar photovoltaic systems. Norway: DNV GL. https://rules.dnv.com/docs/pdf/DNV/RP/2021-03/DNVGL-RP-0584.pdf.

Dörenkämper, Maarten, Arifeen Wahed, Abhishek Kumar, Minne de Jong, Jan Kroon, and Thomas Reindl. 2021. "The cooling effect of floating PV in two different climate zones: A comparison of field test data from the Netherlands and Singapore." Solar Energy 214(2021): 239-247. https://doi.org/10.1016/j.solener.2020.11.029.

Feldman, David, Vignesh Ramasamy, Ran Fu, Ashwin Ramdas, Jal Desai, and Robert Margolis. 2021. U.S. Solar Photovoltaic System Cost Benchmark: Q1 2020. Golden, CO: National Renewable Energy Laboratory. NREL/TP-6A20-77324. https://www.nrel.gov/docs/fy21osti/77324.pdf.

Gadzanku, Sika, Laura Beshilas, and Ursula (Bryn) Grunwald. 2021a. Review of Barriers to FPV Deployment in Southeast Asia. Golden, CO: National Renewable Energy Laboratory. https://www.nrel.gov/docs/fy21osti/76867.pdf.

Gadzanku, Sika, Heather Mirletz, Nathan Lee, Jennifer Daw, and Adam Warren. 2021b. "Benefits and Critical Knowledge Gaps in Determining the Role of Floating Photovoltaics in the Energy-Water-Food Nexus." Sustainability 13(8) 4317. https://doi.org/10.3390/su13084317.

Gordian. 2021. "RSMeans Construction Cost Data." Accessed September 15, 2021. https://www.rsmeans.com/.

Goswami, Anik and Pradip Kumar Sadhu. 2021. "Degradation analysis and the impacts on feasibility study of floating solar photovoltaic systems." Sustainable Energy, Grids and Networks 26, 100425. https://doi.org/10.1016/j.segan.2020.100425.

Hooper, Tara, Alona Armstrong, and Brigitte Vlaswinkel. 2020. "Environmental impacts and benefits of marine floating solar." Solar Energy 219(2021): 11-14. https://doi.org/10.1016/j.solener.2020.10.010.

Horowitz, Kelsey, Vignesh Ramasamy, Jordan Macknick and Robert Margolis. 2020. Capital Costs for Dual-Use Photovoltaic Installations: 2020 Benchmark for Ground Mounted PV Systems with Pollinator-Friendly Vegetation, Grazing, and Crops. Golden, CO: National Renewable Energy Laboratory. NREL/TP-6A20-77811. https://www.nrel.gov/docs/fy21osti/77811.pdf. 
International Renewable Energy Agency. 2019. Future of Solar Photovoltaic: Deployment, investment, technology, grid integration and socio-economic aspects. Abu Dhabi: International Renewable Energy Agency. https://www.irena.org/publications/2019/Nov/Future-of-Solar-Photovoltaic.

Lee, Nathan, Grunwald, Ursula, Aznar, Alexandra, Spencer, Robert, Mirletz, Heather, Cox, Sadie, and Rosenlieb, Evan. 2020. "Hybrid Floating Solar Photovoltaics-Hydropower Systems: Benefits and Global Assessment of Technical Potential". Renewable Energy 162(2020): 1415-1427.

https://doi.org/10.1016/j.renene.2020.08.080.

National Renewable Energy Laboratory. 2021. "2021 Annual Technology Baseline." Accessed September 14, 2021. https://atb.nrel.gov/electricity/2021/data.

Oliveira-Pinto, Sarah and Jasper Stokkermans. 2020. "Assessment of the potential of different floating solar technologies - Overview and analysis of different case studies." Energy Conversion and Management 211(2020): 112747. https://doi.org/10.1016/j.enconman.2020.112747.

Spencer, Robert, Jordan Macknick, Alexandra Aznar, Adam Warren, and Matthew O. Reese. 2019. "Floating Photovoltaic Systems: Assessing the Technical Potential of Photovoltaic Systems on ManMade Water Bodies in the Continental United States." Environmental Science \& Technology 53(3): 1680-1689. DOI: 10.1021/acs.est.8b04735.

U.S. Department of Energy. 2021. Solar Futures Study. Washington, DC: U.S. Department of Energy. https://www.energy.gov/sites/default/files/2021-09/Solar\%20Futures\%20Study.pdf.

U.S. Energy Information Administration. 2020. Annual Energy Outlook 2020. Washington, DC: U.S. Energy Information Administration. https://www.eia.gov/outlooks/aeo/pdf/AEO2020\%20Full\%20Report.pdf.

World Bank Group. 2019. Where Sun Meets Water: Floating Solar Market Report. Washington, DC: World Bank Group. http://documents.worldbank.org/curated/en/579941540407455831/Floating-SolarMarket-Report-Executive-Summary.

Walker, Andy, Eric Lockhart, Jal Desai, Kristen Ardani, Geoff Klise, Olga Lavrova, Tom Tansy, Jessie Deot, Bob Fox, and Anil Pochiraju. 2020. Model of Operation-andMaintenance Costs for Photovoltaic Systems. Golden, CO: National Renewable Energy Laboratory. NREL/TP-5C00-74840. https://www.nrel.gov/docs/fy20osti/74840.pdf. 